\title{
MODELAGEM E DETECÇÃO DE FALHAS EM UM EVAPORADOR DE TRÍPLICE EFEITO PARA CONCENTRAR SODA
}

\author{
J. S. SILVA ${ }^{1}$, S. V. SARAIVA ${ }^{1}$, L. DOMINGUES ${ }^{1}$ e F. O. CARVALHO ${ }^{1}$ \\ ${ }^{1}$ Universidade Federal de Alagoas, Centro de Tecnologia, Curso de Engenharia Química \\ E-mail para contato: samuk_saraiva@hotmail.com
}

RESUMO - Nas indústrias de processos químicos são realizados cada vez mais esforços na tentativa de minimizar falhas, investigar e mitigar o comportamento do processo frente à várias condições operacionais atípicas, e para isso técnicas baseadas em sistemas inteligentes estão sendo cada vez mais aplicadas. Neste trabalho foi realizado um estudo teórico para avaliar a utilização do Mapa Auto-organizável de Kohonen (SOM) na detecção de falhas em evaporadores de tríplice efeito para concentrar soda cáustica. A investigação é realizada em duas etapas: a modelagem do processo para geração de dados e utilização, destes no teste da eficiência da técnica de detecção. Para isso, uma modelagem fenomenológica de evaporadores de tríplice efeito para concentrar soda cáustica através de circulação forçada entre os efeitos foi realizada, apresentando como diferencial a consideração dos efeitos da cristalização do sal nos evaporadores que é posteriormente recuperado. As falhas de processo foram simuladas através da adição de incrementos aos dados simulados das variáveis do processo. Os resultados obtidos pela utilização do (SOM) foram promissores.

\section{INTRODUÇÃO}

Nas indústrias de processos químicos são realizados cada vez mais esforços na tentativa de minimizar falhas. Uma falha é definida como uma variação de no mínimo uma propriedade característica ou variável do sistema (Chiang et al, 2001). Existem diversos tipos de falhas, a título de exemplo podem ser citadas falhas de processo, falhas de sensores e falhas de atuadores. O tipo de falha a ser estudado neste trabalho são as falhas de sensores. Gertler (2008) afirma que falhas de sensores ocorrem quando há discrepâncias entre os valores medidos e os valores reais das variáveis. De uma forma geral todos os tipos de falhas acarretam problemas para as indústrias, em especial a queda na produtividade e paradas para manutenção.

Diversos métodos têm sido desenvolvidos para tarefas de detecção, isolamento e identificação de falhas. Mais precisamente, existem métodos baseadas na elaboração de modelos e baseados em dados. Os métodos baseados em modelos exigem o desenvolvimento de um modelo que detecte e faça o diagnóstico das falhas. Alguns exemplos destes modelos são: modelos multilineares, filtros de Kalman e sistemas especialistas (Chen e Yan, 2012). No 
entanto, a elaboração de tais modelos pode ser bastante tediosa e complexa principalmente em processos químicos, onde um grande número de variáveis está envolvido. Por outro lado, os métodos baseados em dados apenas exigem o histórico de dados de operação. Por esta razão, e levando-se em consideração que nas indústrias de processos um grande número de variáveis é monitorado, as técnicas de detecção de falhas baseadas em dados de operação tornam-se mais atrativas.

Como exemplos de método baseados em dados de operação têm-se Análise de Componentes Principais (PCA) e Redes Neurais Artificiais (RNA). Villegas et al (2010) usou PCA com êxito para detecção e isolamento de falhas em uma planta piloto com dois tanques onde foram simuladas falhas no sensor de nível e obstrução de uma das tubulações.

Com relação às RNA's, a Rede de Kohonen ou Mapa Auto-organizável (SOM) tem se destacado devido a sua versatilidade e aplicações em diferentes áreas. Yan e Chen (2012) utilizaram o Mapa de Kohonen para detecção de falhas e monitoramento do processo Tenessee Eastman e obtiveram resultados satisfatórios.

Germen et al (2014) avaliou a utilização do (SOM) em falhas mecânicas e elétricas que podem ser observadas frequentemente nos motores de indução. A classificação de falhas foi realizada por meio da análise dos dados acústicos dos motores de indução. Análises baseadas em wavelets são aplicadas para filtrar e extrair os recursos necessários dos dados gravados. Os autores concluem que a aplicação do (SOM) se apresentou altamente motivadora, uma vez que possibilitou tanto a separação do motor saudável do defeituoso e na classificação dos tipos de falha.

Khan e Garaniya (2015) propõem utilizar o (SOM) em conjunto com uma análise probabilística para detectar e avaliar o risco de falha em diferentes níveis para permitir uma monitoração refinada de um sistema de controle de pressão e vazão em um tanque. Segundo os autores, os resultados mostraram que a abordagem proposta apresentou uma alta sensibilidade na detecção e identificação da "causa raiz" das falhas, e afirmam que o monitoramento aperfeiçoado facilita a determinação do risco de falha, a implantação antecipada de ações corretivas e medidas de segurança para minimizar o impacto potencial da falha.

Neste trabalho, foi o utilizado o SOM para detectar e isolar falhas de sensores de temperatura em um evaporador de tríplice efeito. As falhas de sensores surgem quando há uma disparidade nos valores medidos de uma variável ou parâmetro, consequentemente, dados de falhas não tem significância estatística o que invariantemente ocasiona problemas futuros no monitoramento do processo. Para a geração dos dados do processo, foi construído o modelo de um evaporador com especificações similares às de um evaporador industrial para concentrar soda cáustica. Fatores como a recirculação de sal entre os efeitos do evaporador, assim como a formação de cristais foram levados em consideração com o objetivo de tornar o modelo robusto. As falhas foram geradas sinteticamente a partir dos dados gerados pelo modelo construído. 


\section{METODOLOGIA}

\subsection{Modelo do Processo}

A modelagem do processo estudado teve como base os trabalhos de Jesus (2004) e Nunes (2006). Esse modelo levou em consideração aspectos intrínsecos do processo, tais como, a cristalização e a mudança das propriedades termodinâmicas através dos efeitos. A Figura 1a ilustra de forma simplificada os evaporadores com a circulação do licor do terceiro efeito ao flash, e a recirculação de sal do primeiro efeito ao terceiro. A Figura 1b, representando o resultado da simulação dinâmica para as temperaturas dos evaporadores, infere que o modelo se comportou em consonância com o comportamento típico de um evaporador com a presença da cristalização e recirculação de sal. O modelo matemático pode ser encontrado em Saraiva (2016).

Figura 1: (a) Esquema do processo de evaporação modelado e (b) comportamento das temperaturas dos efeitos em regime transiente

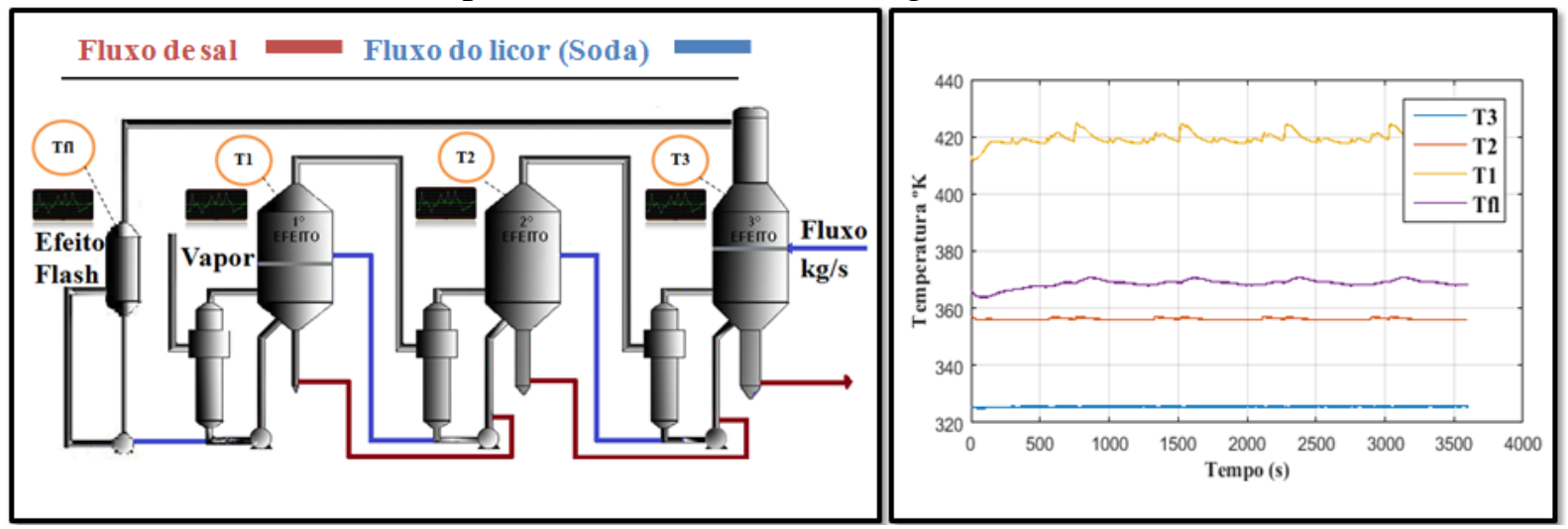

\subsection{Mapa Kohonen}

O Mapa Auto-organizável de Kohonen (SOM) pode ser considerado uma rede neural de aprendizado não supervisionado útil para tarefas de visualização de dados multidimensionais e realização de agrupamentos. O aprendizado não supervisionado caracteriza-se pelo fato de que durante o treinamento apenas dados de entrada são fornecidos à rede. Diferentemente, no aprendizado supervisionado são fornecidos dados de entrada e saída para que a rede neural realize o ajuste ou aprendizado. Em sua forma mais simples, o algoritmo do SOM permite a visualização da similaridade de dados de alta dimensionalidade em uma matriz bidimensional (mapa de características) (Kohonen et al, 1996). Em outras palavras, esta rede neural realiza agrupamentos e isso a torna útil em tarefas de detecção e isolamento de falhas em processos químicos. Por exemplo, esta rede neural pode ser treinada com dados de operação normal e dados com falhas para formar dois grupos e em seguida dados cuja natureza é desconhecida são inseridos no mapa e o grupo no qual estes dados são mapeados permite inferir a respeito de sua natureza.

O SOM possui duas camadas, uma camada de entrada e uma camada de saída. A camada de entrada consiste de um vetor de neurônios, enquanto a camada de saída é uma representação multidimensional de neurônios geralmente bidimensional ou tridimensional 
(Katunin et al, 2015). O número de neurônios na camada de entrada é igual ao número de variáveis nos vetores de entrada. Já na camada de saída, o número de neurônios pode ser estimado através de uma correlação empírica. Vesanto et al (2000) afirma que uma boa estimativa do número de neurônios no mapa é 5 vezes a raiz quadrada do número de amostras de entrada. Durante o treinamento, os vetores ou amostras de entrada que possuem semelhança são mapeados em regiões próximas no mapa. Desta forma, torna-se possível a visualização de clusters ou grupos. No caso de uma tarefa para detecção de falhas os clusters podem corresponder a amostras com falhas ou normais.

Existem várias formas de visualização do SOM. Uma das formas mais populares é a matriz de distâncias unificadas ou Matriz U. A matriz de distâncias tem a finalidade de mostrar a distância entre os neurônios vizinhos em diferentes esquemas de cores facilitando a inspeção visual. Segundo Ultsch e Siemon (1990) a matriz de distâncias é mais favorável para a visualização de grupamentos do que o mapa de características, pois permite identificar distâncias entre grupos com mais eficiência. Neste trabalho foi utilizado o SOM Toolbox, um conjunto de ferramentas em ambiente MATLAB $^{\circledR}$ para implementação e visualização do SOM (SOM Toolbox Team, 1999).

\subsection{Dados}

A partir do modelo desenvolvido foram simuladas 150 condições operacionais, variando-se as pressões dos efeitos e vazões de entrada. As variáveis armazenadas foram: Vazão de licor alimentado $(\mathrm{kg} / \mathrm{s})$, temperatura do licor de entrada $(\mathrm{K})$, Temperatura do primeiro efeito $(\mathrm{K})$, temperatura do segundo efeito $(\mathrm{K})$, temperatura do terceiro efeito $(\mathrm{K}) \mathrm{e}$ temperatura do flash $(\mathrm{K})$. Foram simulados dois tipos de falhas, falha no sensor de temperatura do licor de alimentação $(\mathrm{F} 1)$ e falha no sensor de temperatura do terceiro efeito (F2). As falhas nos sensores de temperatura são as mais comuns pelas condições extremas do processo. Do total de amostras de condições operacionais simuladas foram selecionadas aleatoriamente 30 amostras para ser adicionadas a falha $\mathrm{F} 1$, e 30 para serem adicionadas a falha F2. As falhas F1 e F2 foram sintetizadas adicionando-se um incremento de $20 \%$ nos valores da temperatura do licor de alimentação e na temperatura do terceiro efeito, respectivamente. Desta forma, restaram 90 amostras de condições operacionais normais. Inicialmente, o mapa foi treinado com as 90 amostras de operação normal. Em seguida, foi realizado o teste com as falhas simuladas e foi averiguada a capacidade do SOM frente à detecção e isolamento de falhas.

\section{REULTADOS}

O mapa utilizado possui dimensões [10x6] totalizando um total de 60 neurônios. Como na etapa de teste com falhas foram utilizadas 150 amostras, o número de 60 neurônios é muito aproximado do número fornecido pela fórmula empírica proposta por (Vesanto, 2000). Os resultados obtidos após o treinamento e teste são mostrados nas Fig. 2 abaixo. 


\section{Congresso Brasileiro de Engenharia Química em Iniciação Científica UFSCar - São Carlos - SP 16 a 19 de Julho de 2017}

Figura 2: Matrizes de distância do treinamento, matriz de distância do teste e mapa de características do teste, respectivamente.

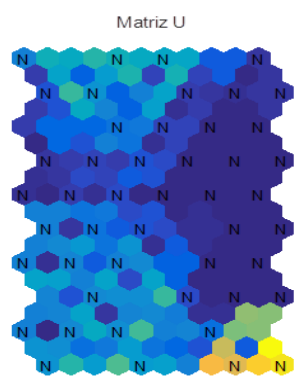

(a)

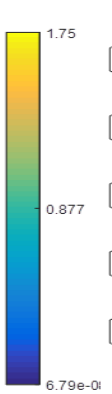

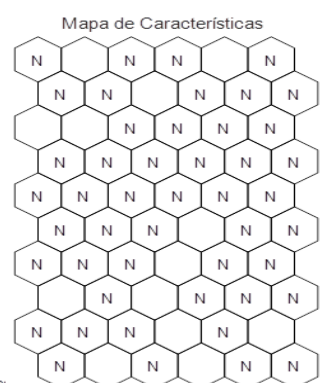

(b)

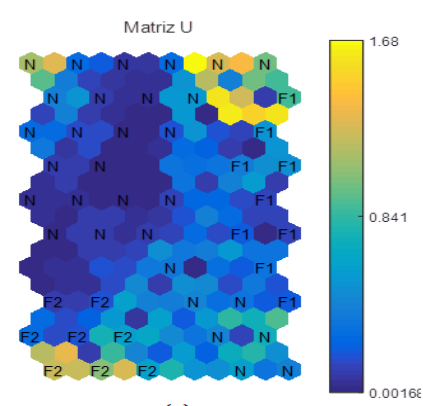

(c)

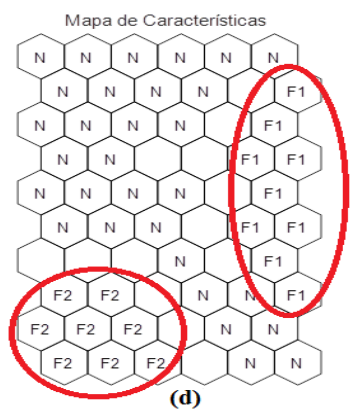

Na Figura 2(a) e 2(b) a matriz de distâncias e o mapa de características mostram que os dados de operação normal não formam um agrupamento uniforme, o esquema de cores indica que existem grandes valores de distâncias entre algumas amostras normais. Após o teste com as amostras com falhas, Figura 2(c) e 2(d), foi observado que as amostras com falhas e normais foram agrupadas com sucesso pelo mapa. Na matriz de distâncias referente ao teste, o esquema de cores revela certo grau de dissimilaridade dentro dos grupos normais, F1 e F2. No entanto, a partir do mapa de características podem ser observados os dois grupos com clareza.

\section{CONCLUSÃO}

Neste trabalho foi apresentada uma investigação da utilização do Mapa Auto organizável de Kohonen (SOM) na detecção de falhas de evaporadores de tríplice efeito para concentrar soda cáustica. Foi observado que para o estudo de caso explorado foram obtidos resultados satisfatórios tanto para a detecção das falhas quanto para o isolamento, uma vez que todas as falhas foram detectadas. Apesar de se tratar de uma investigação teórica, na qual a representatividade dos dados frente a uma planta real pode ser comprometida, pode-se afirmar que essa técnica pode ser facilmente aplicada para monitoramento online de processos reais.

\section{REFERÊNCIAS}

CHIANG, L. H.; RUSSELL, E. L.; BRAATZ, R. D. Fault Detection and Diagnosis in Industrial Systems. Springer. 2001.

GERMEN, E., BAŞARAN, M., FIDAN, M. Sound based induction motor fault diagnosis using Kohonen self-organizing map. Mechanical Systems and Signal Processing. pp. 45-58. 2014.

GERTLER, J.J. Fault Detection and Diagnosis in Engineering Systems. CRC Press, 1998.

JESUS, C. D. F. Validação da simulação dinâmica das etapas de evaporação e cristalização da produção de açúcar com dados obtidos em plantas industriais. Tese de doutorado de São Carlos -SP, 2004.

KATUNIN, A., AMAROWICZ, M., CHRZANOWSKI, P. Fault Diagnosis Using SelfOrganizing Maps: A Case Study On The Damadics Benchmark Problem. Proceedings 
of the Federated Conference on Computer Science and Information Systems. pp. 16731681. 2015.

KOHONEN, T., OJA, E., SIMULA, O., VISA, A., KANGAS, J. Engineering Applications of the Self-organizing Map. Proceedings of the IEEE. 1996.

NUNES, C. A. M. Modelagem e avaliação de evaporadores de tríplice efeito para concentração de soda cáustica em estado estacionário. Dissertação de Campina Grande, 2006.

SARAIA, S. V., CARVALHO, F. O. Modelagem Modelagem Fenomenológica De Evaporadores De Tríplice Efeito Para Concentração De Soda Cáustica, Visando À Avaliação Da Ferramenta Computacional Para A Detecção De Falhas. Caiite (Congresso acadêmico integrado de inovação e tecnologia. Maceió, Alagoas, 2016.

SOM Toolbox Team. http://www.cis.hut.fi/projects/somtoolbox/documentation/. 1999.

ULTSCH, A.; SIEMON, H. P. Kohonen's Self Organizing Feature Maps for Exploratory Data Analysis. Proceedings of the International Neural Network Conference. Dordrecht, Netherlands. 1990.

VESANTO, J.; ALHONIEMI, E. Clustering of the Self-organizing Map. IEEE Transactions on Neural Networks. Vol. 11, No. 3, pp. 586-600. 2000.

VILlEGAS, T., FUENTE, M., RODRÍGUEZ, M. Principal Component Analysis for Fault Detection and Diagnosis. Experience with a Pilot Plant. Advance in Computational Intellingence, Man-Machine Systems and Cybernetic. 2010.

YAN, X., CHEN, X. Using Improved Self-organizing Map for Fault Diagnosis in Chemical Industry Process. Chemical Engineering Research and Design. Elsevier. 2012.

YU, H., KHAN, F., GARANIYA, V. Risk-based fault detection using Self-Organizing Map. Reliability Engineering and System Safety. pp 82-96. 2015. 